\title{
-14-Giardin (annexin E1) is associated with tubulin in trophozoites of Giardia lamblia and forms local slubs in the flagella
}

Anke Vahrmann • Mirela Šarić • Ilona Koebsch • Henning Scholze

Published online: 23 November 2007

(C) Springer-Verlag 2007

Erratum to: Parasitol Res

DOI 10.1007/s00436-007-0758-6

Unfortunately the order of author names has been misprinted in the original publication.

The correct order of author names is given here:

A. Vahrmann, M. Šarić, I. Koebsch, H. Scholze

The online version of the original article can be found at http://dx.doi. org/10.1007/s00436-007-0758-6.

\footnotetext{
A. Vahrmann • M. Šarić $\cdot H$. Scholze $(\bowtie)$

Department of Biology/Chemistry, Biochemistry,

University of Osnabrueck,

49069 Osnabrueck, Germany

e-mail: scholze@biologie.uni-osnabrueck.de

I. Koebsch

Department of Biology/Chemistry, Applied Genetics,

University of Osnabrueck,

49069 Osnabrueck, Germany
} 